\title{
Towards a Sustainable Distribution and Effective Management of School Facilities in Ikot Ekpene LGA of Akwa Ibom State: A Geographic Information Systems Option
}

\author{
Akpan, Patrick Etim \\ Department of Urban and Regional Planning, \\ Akwa Ibom Sate Polytechnic, Ikot Osurua, Nigeria \\ Njoku, Elijah Akwarandu \\ Department of Geography and Regional Planning, \\ University of Benin, Nigeria.
}

\section{Doi:10.5901/mjss.2013.v4n16p77}

\begin{abstract}
The study investigated the spatial distribution of school facilities in Ikot Ekpene LGA of Akwa Ibom State, Nigeria with a view to apply Geographic Information Systems (GIS) technique in educational facilities management planning. The study used the administrative map of the study area collected from the local government as the base map. Information on the number and addresses of the educational facilities available in the study area were collected from the State Secondary Board, Uyo while the coordinates of the schools were obtained during field survey using Global Positioning System (GPS). These data were incorporated into GIS environment and analysed using Arc Map 9.3 software. The study revealed a random to near concentration of the schools in particular wards in the LGA with some left areas educationally deprived. The study also shows the pattern of facilities distribution in the study area.
\end{abstract}

Keywords: School facilities, GIS, Mapping, Creation of Database.

\section{Introduction}

Education is widely seen as one of the most promising paths for individuals to realize better and more productive lives and as one of the primary drivers of national economic development. It is a decisive determinant of economic and social expansion, household livelihoods and food security status. As a basic human right, education is indispensable for the realization of other human rights and it is a means for accessing broader social, economic, political and cultural benefits. Because it is transformative and empowering, education contributes to building more just societies through reducing poverty and inequalities, enhancing acceptance of diversity, and promoting respect for the rule of law (Aliyu, Sule and Youngu 2012). No doubt educational development depends on a large number of factors; but the role of school infrastructural facilities in successful educational programs has been outstanding. Perhaps, because of their strategic importance, the quality and quantity of school infrastructural facilities receive much attention in any effort to raise the educational level of a given area. School facilities are those things that enable the teacher to efficiently discharge his/her responsibilities and help the learners to learn effectively. These include classrooms, chalkboard, laboratories, workshops, libraries, different kinds of furniture, films, magnetic tapes and related facilities. Ayeni and Adelabu, (2012) have observed that school infrastructure and equipments contribute to a conducive learning environment. Also, other indoor and outdoor infrastructural components such as open space, ventilation and insulation from heat including urinals and toilets have been found to 
have significant impacts on the quality of learning (Lawanson, Olukemi \& Tari, 2011). However, while these facilities are germane in realizing a successful teaching and learning project, if they are provided and or located in a spatially random manner access to such facilities and hence their utilization would be highly limited. Therefore, issues of location, accessibility and utilization of school facilities are a necessary concern for those concerned with location of such facilities. For centuries, the task of efficiently locating both public and private facilities to ensure utilization and access has attracted a significant research attention. This is imperative in view of the impact of spatial location decisions on access and utilization of facilities.

Pursuant to the attainment of Millennium Development Goals and Vision 2020:20, Ikot Ekpene LGA of Akwa-Ibom state and indeed the entire state has continued to invest heavily in the provision of quality education to its citizenry. In this regard, the LGA has paid attention to the development and provision of both human and school infrastructural resources to ensure the attainment of the desired level and quality of education within its jurisdiction. However, to ensure equitable distribution and efficient management of the facilities in the LGA as well as guarantee maximum access and utilization of the facilities by the target population, there is the need to create a data base of the facilities in an easily querryable manner as well as ascertain the current distributional pattern of the available facilities in the LGA. In the past decades, geographers and spatial planners have engaged in such locational exercise in a pencil-and-paper manner in attempt to determine and map optimum locational pattern of phenomena of interest. While this method proved helpful to a large extent, it has obvious serious computational and visualization limitations. For instance, computing different possible optimum locations of a facility in a hierarchical manner based on a given mix of location and accessibility criteria has almost always proved manually inefficient and unworkable. Also, visual representation of such locations and management of related data in an easily querryable and searchable format has been sufficiently challenging. With the advent of Geographical Information System (GIS) however, locational decisions and database construction on spatial phenomenon such as school facilities have become more efficient and robust. GIS is a system for managing, storing, analyzing, modeling and visualizing spatial information. Visualization with GIS usually takes the shape of maps, simulations and 3D models using satellite or air-borne remotely sensed imageries (Lo and Yeung, 2007). One of the earliest forms founded in the 1960s was Canada Geographic Information System, which was built for the collection and analysis of spatial data. Because of its capability and multidisciplinary applicability, the use of GIS has witnessed an explosive growth since then. One important GIS capability is in handling both digital cartographic data and the associated databases of attribute information for map features (Burrough, 2001). GIS systems can store and map coordinates of point locations, linear and areal features. These features have attributes that must be stored in the database. Once all the data are stored, both the digital map and the database can be manipulated simultaneously. GIS can contribute to the development of a robust and efficient school infrastructure management by suggesting optimum location and organization of the facilities needed. This has the potential to lead decision makers to the selection of the best and less costly system that might improve citizen's access to education. Scientists use GIS as a method and tool that provides outstanding results in the understanding of location and its relation to other variables (UN Report, 2004)

In the current paper, GIS is used to capture, analyze and visualize available data on school facilities in the study area. Specifically, the study evaluated the spatial distribution of secondary schools and educational facilities within Ikot Ekpene LGA. To achieve the above aim the following objectives were set:

- $\quad$ to map spatial distribution of public secondary schools in Ikot Ekpene LGA .

- to take inventory of educational facilities and schools within the study area.

- to create database for educational facilities management in the study area

\section{Geographical Setting of the Study Area}

Ikot Ekpene is located between latitudes $5^{\circ} 10^{\prime}$ and $5^{\circ} 30^{\prime}$ North and longitudes $7^{\circ} 30^{\prime}$ and $7^{\circ} 45^{\prime}$ East. It lies on the North-Western flank of Akwa Ibom State. Its position makes it one of the economic gateways to 
Akwa Ibom State. Ikot Ekpene is historic local government administration in Nigeria, as it became a premier model local government administration in 1951. Today, Ikot Ekpene is the headquarters of Ikot Ekpene Senatorial District that has altogether 10 Local Government Areas. The town is located on the highway that parallels the coast, between Calabar to the south east and Aba to the west, with the state capital, Uyo. Umuahia is the next major town to the north. Ikot Ekpene is a known as a regional centre of commerce, with notable exports of palm products, especially palm oil, kernels, raffia products including raffia fibers and its sweet wine, as well as ground crops of yams, cassava, taro, and corn which attract large population from the neighbouring town.

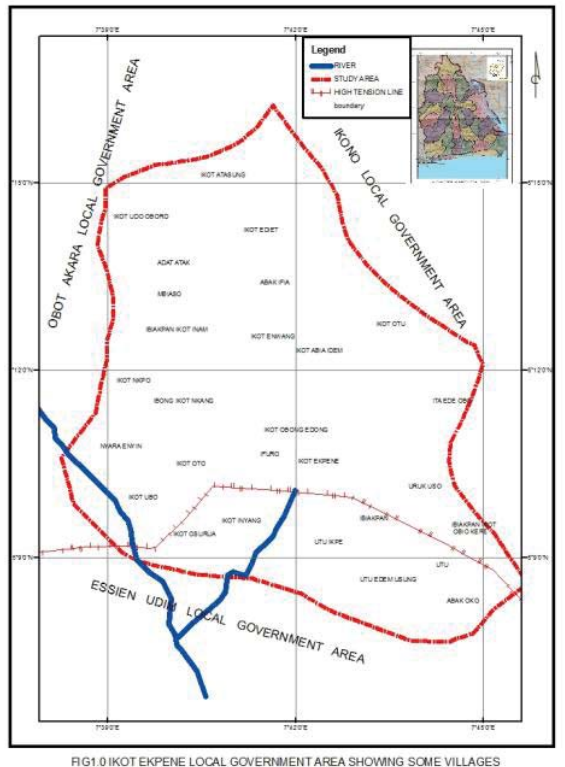

\section{Methodology}

The study used data containing the comprehensive list of schools and educational facilities and their coordinates in Ikot Ekpene LGA, sourced from Sate Secondary School Board, Uyo. Administrative map of Ikot Ekpene LGA was also acquired from the local government to serve as the base map. Global Positioning System (GPS) was used to collect coordinate points of the schools in the local government as in table 1.1below. Questionnaires were issued to every school in order to acquire facility information. The data was disaggregated according to points location of schools (fig.1.1) A GIS-readable database was created using Microsoft excell 2007 and ArcGIS 9.2 software. The location of each school was used to analyze general spatial distribution of schools within the study area.

Also, a street by street search was conducted in order to capture all the schools and their facilities in the study area. Data collected include: name of the school, address, number of classes, availability of laboratories, toilet facilities and number of blocks in each school. Duplicate information (also called redundant data) was avoided in order not to introduce errors and inconsistencies in the database, correctness and completeness of information were made paramount. The database design involved gathering all of the types of information desired to be recorded in the database, such as Name/Address of school, System of study, Average number of pupilslstudents per class room, Internet/Laboratory access, Tuition fees. It also provides for adequate linking, retrieval, updating of data. Data for the database building was entered in Microsoft excel and saved in tab delimited format which is recognizable and acceptable to the ArcCatalog extension of ArcGIS. ArcCatalog allows the user to easily access and manage geographic data that is stored in folders on 
local disks or relational databases that are available on the user's network. Data can be copied, moved, deleted, and quickly viewed before it is added to a map. The analogue map was scanned and stored in the ArcCatalog extension. The map was opened in the ArcMap environment where it was digitized in one layer for the features on the features (major roads and minor roads) and the tables held in the ArcCatalog extension were added, using the add XY 'command' at the tools menu. The system can be updated to reflect changes in any school information such as class room blocks etc, as well as appending more attributes in ArcGIS interface. To determine the deprived areas, buffering analysis was carried out based on planners' view point of minimum walkable distance of $1 / 4 \mathrm{~km}$ and later dissolved to ascertain the zone of influence. (See figure 1.5).

Table 1.1: The database for private and public school in ikot ekpene local government (2013)

\begin{tabular}{|c|c|c|l|c|}
\hline S/N & X Value Longitude & Y Value Latitude & \multicolumn{1}{|c|}{ Name/Address } & Ownership \\
\hline 01 & 0355609 & 0573142 & Holy Child Secondary School,Abaroad Ikot Ekpene & Missionary \\
\hline 02 & 0356842 & 0574350 & Lutheran High School, Lutheran Road. & Missionary \\
\hline 03 & 0355925 & 0574538 & Ritman College,Umuhia Road Ikot Ekpene & Private \\
\hline 04 & 0355809 & 0575284 & Community Secondary School, Mbiaso & Puplic \\
\hline 05 & 0357812 & 0575013 & Foundation College Of Technology & Private \\
\hline 06 & 0357837 & 0574976 & Garden Seccondary School & Private \\
\hline 07 & 0357980 & 0574881 & Edemsco Secondary School & Private \\
\hline 08 & 0358055 & 0574312 & Kingdom Heritage Secondary, Ikot Ekpene & Private \\
\hline 09 & 0357875 & 0573974 & State Secondary Okop Eto, Abia Okpo & Private \\
\hline 10 & 0357745 & 0573827 & Modern Secondary School, Abiakpo & Private \\
\hline 11 & 0357603 & 0572994 & Urban High School, Chubb Road & Private \\
\hline 12 & 0356564 & 0571283 & Goretti Girl Secondary, Spring Road & Missionary \\
\hline 13 & 0357639 & 0570638 & State College, Abak Road, Ikot Ekpene & Public \\
\hline 14 & 035444 & 0510472 & Federal Government College, & Public \\
\hline 15 & 0374349 & 0550841 & Ndon Ide Secondary School, Ikot Ekpene. & Public \\
\hline
\end{tabular}

Source: Author's field survey, 2013

The result of the data set for private and public school is as displayed in table 1.1. It shows the coordinates, names and addresses of the 15 secondary schools in the study area. From table 1.1, it can be observed that there were more private secocndary schools $9(60 \%)$ than public secondary $6(40 \%)$. The spatial distribution of the public and private secondary schools as mapped is also shown in figure 1.2

\section{Database Creation, Manipulation and Analysis}

The analysis consisted of stages. The first being the creation of thematic maps via the GIS in order to provide a visual portrayal of the spatial distribution of schools and levels of facilities available. Thematic mapping is a GIS tool that is used to display the spatial variation of a single theme (in this case school facility). The second analysis was carried out using querying using the query builder and buffering analysis. The query builder tool is accessed by clicking on selection on the menu bar and pointing to 'Select By Attributaes' and clicking. A dialog box appears. The query expression is built either by typing it in or clicking on the required fields, operators and values in the dialog box.

The queries and some analysis performed were:

* What are the spatial pattern of school facilities distribution in Ikot LGA

* What are the spatial distribution of secondary schools are in Ikot Ekpene LGA

- What are spatial distribution of schools within walkable distance in Ikot Ekpene LGA

* What are the percentage distribution of schools within the study area 
Where are the area that can access schools within 1/4mile as stipulated by planners

* How many schools do not have functional library

* Which sections within the study area are deprived in term of educational facilities

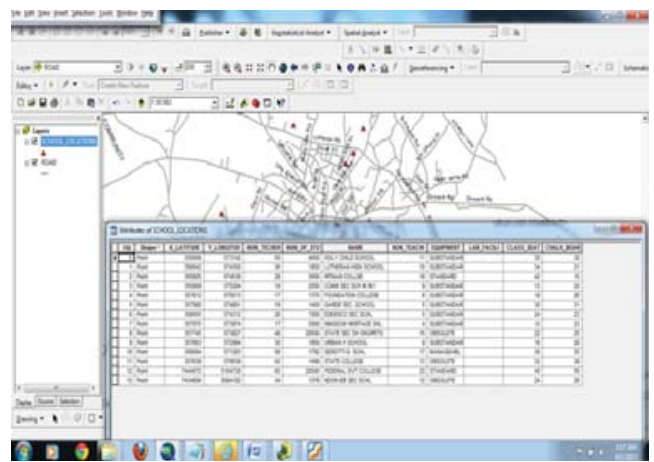

Fig. 1.1: Database of educational facilities in the study area

It is possible from figure 1.1 above to find out how many schools are in a particular locality. Other information includes the total number of pupils, teachers, children and the total population in the locality. The exact geographic location of each school is also provided. This set of information is indispensible for planning purposes.

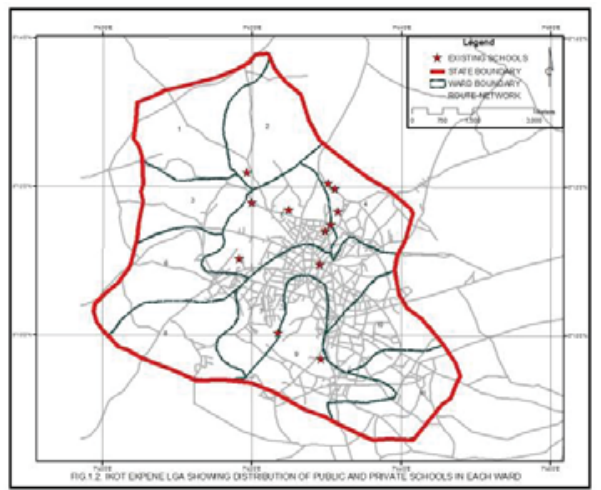

Figure 1.2: Reveals a random but near clustered distribution of the schools.

\section{Results and Discussion}

The study identified the educational facilities in Ikot Ekpene LGA including their geometric properties and created a GIS database for both the public and private schools in the study area as shown in fig.1.1. It is obvious from the analysis (see fig-1.2) that spatial location of schools in the LGA is uneven and almost randomly distributed such that some wards are essentially educationally deprived. For instance, Ward 4 and 5 have the highest density of schools and infrastructure. In terms of accessibility and optimal location pattern, planners often consider a $1 / 4$ kilometre distance from a location as being the maximum distance that people are willing to walk to access products and services. Thus, Figure 1.3 shows $1 / 4$ kilometre mile rings of accessibility to schools in Ikot Ekpene. This reveals the spatial distribution of the schools as well as evident deprivation in some portions of the LGA. In proposing the sites for the location of new schools, buffering analysis was done as shown in figure 1.3 and areas outside the buffered zone was selected as a potential area for locating new schools using $1 / 4 \mathrm{~km}$ physical distance threshold. The buffer rings (in Figure 1.3) were 
generated as the crow flies, i.e., it did not take into account the actual paths that people may need to access the school. Areas outside the ring are deprived areas in terms of accessibility to school. The result demonstrates the

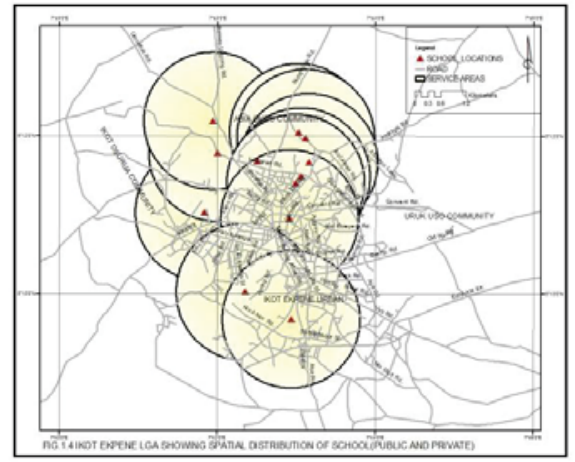

The Figure 1.3 shows $1 / 4 \mathrm{~km}$ buffers around the school location. Buffering is a common GIS technique and can be used to quickly identify a geographic area that is considered accessible or walkable to a given location.

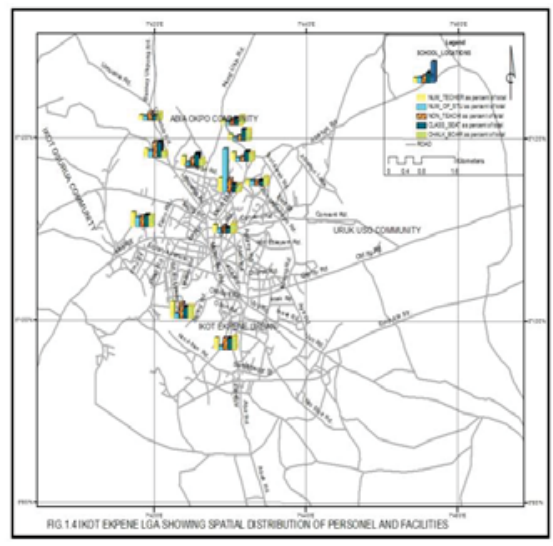

The above figure actually displayed the percentage distribution of personnel and other basic facilities in each school. These include: chalk board, number of seats, and classroom blocks, etc.

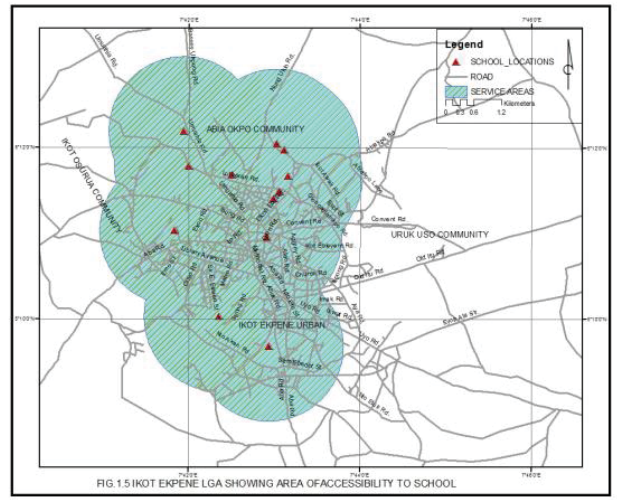


Figure 1.5 shows areas of coverage within the study area. The buffers shows areas providing adequate educational services. Villages within this zone have good access to education than those outside the buffer. This means that communities such Uruk Uso and part of Ikot Osurua has very limited access to educational facilities when compared to other communities within the study area.

Ability of GIS to display locational information of geo-based phenomena together with useful attribute data. A searchable database was queried in figure 1.1 and 1.6 to determine basic characteristics of the schools in question. In this query, information about the name, address, year of establishment, number of male and female pupils, number of teachers (male and female), and the geographic location of the schools are available. With such a robust data constructed on the schools and analysed using GIS, management decision of such schools in terms of location and facilities becomes easy and highly informed. The percentage share of each school from the total school number of students, class rooms, academic staff, nonacademic staff, etc shows some equity with the exception of ward 3 in Mbiaso community secondary school with a relatively higher number of students, few seats and other basic facilities. Over all, locational pattern of schools in the study area could be said to be mildly random to fairly concentrated. To ameliorate this problem, new potential sites to ensure optimum location have been suggested.

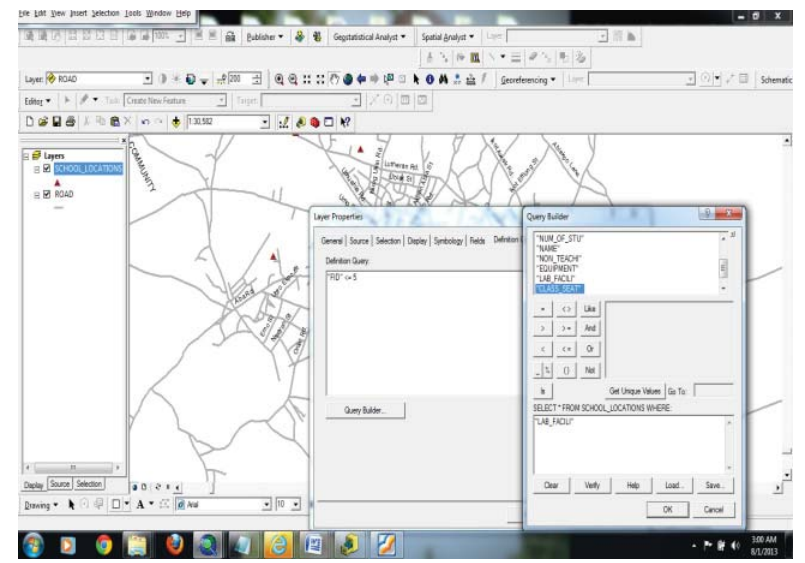

Fig. 1.6: Displays the result of query on the schools without library in the study area.

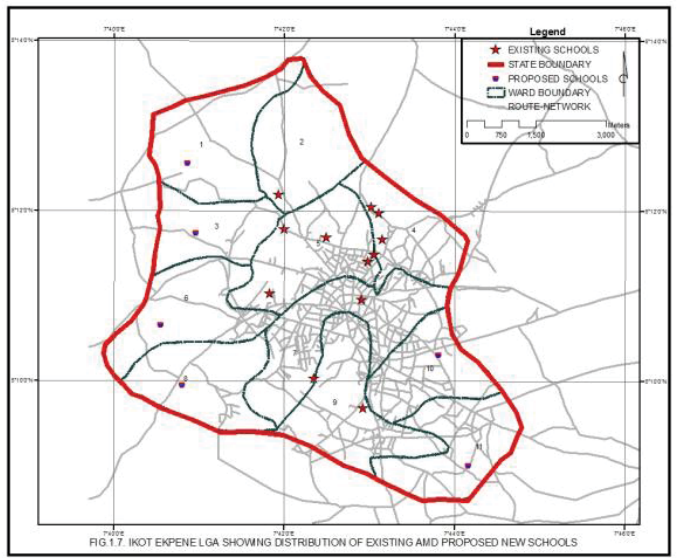

This figure shows suggested location of new schools based on the buffered analysis in figure 1.5 to enhance effective accessibility within study area 


\section{Conclusion}

Efficient location of facilities, especially publicly-owned facilities, is the goal of both the public decision maker and the government in general. That notwithstanding, achieving this feat has constituted an intractable problem over the years. Geographical Information System has enviable capacity to store capture, store, analyse and output geographical data in a way that is helpful in many decision-making contexts. By the use of GIS, current study has revealed serious spatial inequality in the distribution of both private and public schools in the study area. Such spatial inequality must be avoided given its enormous financial and time implications in accessing and utilizing these facilities. Also, given poor state of Nigerian roads and very low standard of living of the citizenry, poor locational planning of facilities like schools will substantially limit utilization of such facilities and hence aggravate already bad situation, In this regard, the utility of GIS cannot be over emphasized. GIS technology has the potential to revolutionize education monitoring by giving policy maker quick and easy access to large volume of both processed and analyzable data. GIS is valuable in strengthening the whole process of education information management and analyses. No doubt GIS provides analytical support for the planning, programming, and evaluation of activities and interventions in the educational sector.

\section{References}

A. J. Ayeni and M. A. Adelabu, (2011) "Improving Learning Infrastructure and Environment for Sustainable Quality Assurance Practice in Secondary Schools in Ondo State, South-West, Nigeria,"International Journal of Research Studies in Education, Vol. 1, No. 1, 2012, pp. 61-68. doi:10.5861/ijse.2012.v1i1.20.

Burough, P. 2001. Principles of Geographical Information System, Spatial Information systems and Geostatistics. New York: Oxford University Press. 20p.

C. P. Lo and Albert K. W. Yeung(2007), concept and Technique of Geographic Information Systems, pearson Prentice,Upper Saddle River, New Jewjersey.

Hite, J. (2004). GIS in Education Planning and Manage-ment: A Training Module created for the IIEP/UN-ESCO. Directions in educational planning: Symposium

Lawanson, Olukemi Anike Gede, Ngozi Tari ,(2011) Provision and Management of School Facilities for the Implementation of UBE programme journal of Educational and Social research Vol. 1 (4) November 2011

Longley, P.A., Goodchild, M.F., Maguire, D.J. and Rhind D.W. (2001). Geographic Information Systems and Science, John Wiley and Sons, Chichester.

United Nations Educational, Scientific and Cultural Or-ganization, (2004). "India-National Report of the Development of Education," 47th Session of the International Conference on Education Geneva, 8-11 September 2004. http/ww.ibe.unesco.org/Internal//CE47/English/Natreps/reports/india.pdfhttp.

Y.A. Aliyu, J.O. Sule and T.T. Youngu (2012), Application of Geospatial Information System to Assess the Effectiveness of the Millennium development goal Target in Amac Metropolis-Abuja, Nigeria. Research Journal of Environmental and Earth Sciences 4(3): 248-254, 2012. Maxwell Scientific Organization. 